\title{
Arboviroses: Estudo Longitudinal de Casos de Dengue
}

\author{
Arboviruses: Longitudinal Study of Dengue cases
}

Victor Fellipe Justiniano Barbosa ${ }^{\dagger,}$, Adriano Garcia Ferreira ${ }^{\dagger,}$, Igor Luiz Souza da Cruz ${ }^{\dagger, \S, \|, o}$, Sebastião Jorge da Cunha Gonçalves ${ }^{\ddagger}$, Marco Orsini॰, Marise Maleck ${ }^{\dagger, t}, \|, \mathrm{O}^{*}$

Como citar esse artigo. Barbosa

V.F.J.; Ferreira, A.G.; da Cruz, I.L.S.; Gonçalves, S.J.C.; Orsini, M.; Maleck, M. Arboviroses: Estudo Longitudinal de Casos de Dengue. Revista de Saúde. 2019 Jul./Dez; 10 (2): 31-36.

\section{Resumo}

A dengue configura-se atualmente como a arbovirose mais prevalente no mundo. Cem milhões de habitantes de países tropicais se infectam, por ano, com o vírus causador da dengue, que é hoje objeto da maior campanha de saúde pública do Brasil. O objetivo deste estudo foi analisar os casos de dengue notificados no município de Vassouras, Estado do Rio de Janeiro, RJ. O levantamento foi realizado a partir dos boletins epidemiológicos colhidos na Superintendência de Vigilância em Saúde (SVS), da Secretaria Municipal de Saúde do Município de Vassouras, RJ. Foram identificadas as áreas mais acometidas com casos de suspeita de dengue e realizada uma análise comparativa dos dados colhidos no período de 2014 a 2017. De acordo com os dados obtidos, a área Grecco manteve-se em destaque por apresentar números elevados de notificações de casos em três anos consecutivos, durante a abrangência deste estudo. Os maiores índices em 2 anos consecutivos pertencem as áreas do Centro, Madruga e Carvalheira. Ao analisar o período de maior ocorrência, a estação mais crítica foi o outono, com maior número de notificações da doença. Este estudo possibilitará um controle mais eficaz desta arbovirose no município de Vassouras.

Palavras-chave: Dengue; Arboviroses; Saúde Pública.

\begin{abstract}
Dengue currently configures itself as the most prevalent arbovirosis in the world. One hundred million inhabitants of tropical countries infect each year with the virus that causes dengue, which is now the object of the largest public health campaign in Brazil. The objective of this study was to analyze the cases of dengue reported in the municipality of Vassouras, State of Rio de Janeiro, RJ. The survey was carried out from the epidemiological bulletins collected at the Superintendência de Vigilância em Saúde (SVS), of the Secretaria Municipal de Saúde of the Municipality of Vassouras, RJ. The most affected areas with suspected dengue cases were identified and a comparative analysis of the data collected in the period from 2014 to 2017 was performed. According to the data collected, the Grecco area maintained a number of case reports in three consecutive years of coverage of this study. And the highest rates in two consecutive years showed the areas of Centro, Madruga, and Carvalheira. When analyzing the period of greatest occurrence, the most critical season was autumn, with a greater number of reports of the disease. This study will enable more effective control of this arbovirosis in the municipality of Vassouras.
\end{abstract}

Keywords: Dengue; Arboviruses; Public health.

\section{Introdução}

A dengue é uma doença infecciosa causada por um arbovírus e transmitida pelo mosquito Aedes aegypti (Linnaeus, 1762). O agente etiológico, que pertence à família Flaviridiae, apresenta quatro sorotipos distintos, denominados DEN-1, DEN-2, DEN-3 e DEN-4'1. Essa doença é comum em zonas tropicais e subtropicais, que possuem clima quente e úmido $2-3$ o qual pode ser encontrado no município de Vassouras, RJ.
A dengue configura-se atualmente como a arbovirose mais prevalente no mundo, com cerca de $40 \%$ da população em risco ${ }^{4}$. O número de casos da dengue clássica $(\mathrm{DC})$ e da febre hemorrágica do dengue (FHD) vem aumentado anualmente. Estima-se $550 \mathrm{mil}$ internações com 20 mil óbitos anuais em um total de aproximadamente 2,5 bilhões de pessoas expostas ${ }^{5}$ e uma média de 80 a 100 milhões de casos novos notificados anualmente ${ }^{6}$. No Brasil, a introdução da dengue com confirmação laboratorial data de meados

- Professor da Escola de Medicina da Universidade Iguaçu, Nova Iguaçi, RJ, Brasil

* Email de correpondência: marise.maleck@gmail.com 
de 1981 a 1982, na cidade de Boa Vista, Estado de Roraima, Amazônia brasileira, onde foram isolados os sorotipos DEN 1 e 4 , e sendo registrada a primeira epidemia de dengue no Brasil, com aproximadamente 11 mil casos. Desde então, o país passou por diversos surtos epidêmicos ${ }^{3,7}$. Atualmente, a dispersão do $A$. aegypti atinge as 27 Unidades Federadas, com mais de 3.587 municípios infestados pelo vetor da doença ${ }^{3}$.

A infecção pelo vírus do dengue resulta em um amplo espectro clínico patológico, variando de um quadro assintomático até quadros sintomatológicos de Febre do Dengue (FD), quadros graves de Febre Hemorrágica do Dengue (FHD) e Síndrome do Choque do Dengue (SCD), em que o paciente pode evoluir para instabilidade hemodinâmica, com manifestações hemorrágicas como petéquias, epistaxe, gengivorragia, sangramento gastrointestinal, hematúria e metrorragia, que geralmente cursam com hipotensão arterial, trombocitopenia e taquisfigmia ${ }^{8-11}$. Em quadros graves, essas manifestações podem provocar choque séptico e/ou hipovolêmico e resultar em óbito ${ }^{9-12}$. Indivíduos infectados com um sorotipo viral adquirem imunidade duradoura específica para o tipo viral infectante, mas não para os outros três tipos. Pessoas que moram em áreas endêmicas do dengue podem apresentar várias infecções por sorotipos diferentes no decorrer da vida. Observações epidemiológicas sugerem que infecções sucessivas por diferentes sorotipos aumentam o risco de desenvolver FHD. No entanto, existem outras hipóteses de gravidade de quadro clínico como o subtipo viral infectante $\mathrm{e}^{10,13}$.

Dessa maneira, essa doença configurou-se nas últimas décadas como importante causa de morbidade e mortalidade no Brasi $1^{13}$. Em termos de número de casos, representa a doença mais importante transmitida por vetor no Brasil e a segunda mais importante doença transmitida por vetor no mundo ${ }^{14}$, ficando abaixo apenas da malária.

Com o crescente número de casos de dengue, esta tornou-se alvo de preocupação em todo o estado do Rio de Janeiro. De acordo com os boletins epidemiológicos semanais de número 1 a 24 emitidos pela secretaria de estado de saúde e defesa civil e Superintendência de Vigilância em Saúde do município de Vassouras, nesta cidade houve um aumento considerado nos casos notificados no primeiro semestre do ano de 2015 em comparação ao mesmo período de 2014. Isso se configura como um problema de saúde pública e preocupa as autoridades de saúde e a população em razão da possibilidade de uma epidemia e das possíveis consequências em indivíduos acometidos com formas graves. Este fato justifica este estudo, que é realizado paralelamente, pela mesma equipe, com o levantamento populacional do mosquito no município, e com a conscientização da população local. Em conjunto, estes tornam-se um monitoramento em rede, utilizando as notificações realizadas neste estudo comparadas com a presença do vetor. Com estes dados é possível estabelecer um programa de controle mais eficaz no município, direcionado aos locais mais infestados pelo vetor e do maior número de casos notificados, além de levar à população as melhores formas de monitorar 0 mosquito e controlar a doença.

O presente estudo teve como objetivo catalogar as áreas endêmicas e acompanhar a progressão do número de casos de dengue no município de Vassouras, a fim de possibilitar o aprimoramento das medidas de controle do vetor e prevenção da doença, levando em consideração as áreas mais acometidas do município e o período do ano de maior ocorrência.

\section{Material e Métodos}

A área de estudo, o município de Vassouras, RJ, possui $552 \mathrm{~km}^{2}$ e população de 34.410 habitantes $^{14-15}$, e está localizado a $22^{\circ} 24^{\prime} 14^{\prime \prime} \mathrm{S}$ e $43^{\circ} 39^{\prime} 45^{\prime \prime} \mathrm{O}$, com 434 $\mathrm{m}$ de altitude, clima mesotérmico úmido, associado à Floresta Temperada Úmida, com temperatura média anual de $16^{\circ} \mathrm{C}$ a $28^{\circ} \mathrm{C}$.

O município de Vassouras caracteriza-se por ser uma cidade universitária e turística, e possuir um grande fluxo populacional. Este fato contribui para o aparecimento de novas doenças e para o ressurgimento das erradicadas. O levantamento de casos foi realizado a partir dos boletins epidemiológicos, colhidos na Superintendência de Vigilância em Saúde (SVS), da Secretaria Municipal de Saúde do Município de Vassouras, RJ. O período de monitoramento compreendeu de janeiro de 2014 a dezembro de 2017, com um período total de 4 anos. Os dados foram analisados e expressos em valores absolutos de maneira comparativa entre os anos de estudo, averiguando a quantidade total notificada de casos de suspeita de dengue e de óbitos (caso tenham ocorrido). Além disso, também foram analisados as áreas e o período do ano de maior prevalência da doença.

\section{Resultados}

De acordo com os dados obtidos, no ano de 2014, foram enviadas ao Laboratório Central de Saúde Pública do Rio de Janeiro, Instituto Noel Nutels (LACENN), instituição competente em realizar procedimentos laboratoriais de maior complexidade para complementação de diagnóstico, 21 amostras de sangue coletadas de pacientes residentes no município de Vassouras enquadrados como portadores de um quadro clínico suspeito de dengue. Destas 21 amostras, 11 foram confirmadas como casos de dengue pelo LACENN. Nos anos de 2015, 2016 e 2017 foram enviadas, pelo 
município, 63, 73 e 9 amostras e sendo confirmadas 14, 3 e 1, respectivamente. Em números absolutos, no ano de 2014 ocorreu um total de 68 casos notificados na SVS municipal, e em 2015, 2016 e 2017 ocorreram, respectivamente, 1115,565 e 65 notificações de casos com suspeita de dengue (Figura 1). Notificações estas, realizadas pelos hospitais, unidades básicas de saúde ou qualquer indivíduo podendo ou não ser um profissional da saúde, através do preenchimento de uma ficha de notificação compulsória e envio à SVS municipal. As áreas com maior número de notificações de casos de suspeita de dengue, em números absolutos (obtidos pelos boletins epidemiológicos fornecidos pela SVS) no ano de 2014 foi a área do Grecco, com 24 notificações. No ano de 2015 prevaleceram as áreas Residência, Madruga Centro, Carvalheira e Grecco com índices superiores a 50 notificações (Figura 2).

No ano de 2016 observou-se que a área do Madruga e do Centro atingiram números superiores a 80 notificações. Em 2017, houve uma redução significativa de números de notificação em todas as áreas observadas neste estudo (Figura 3).

As áreas também com casos notificados, mas todos com índices totais durante os quatro anos de estudo, destaca-se o Mancusi com 47 casos no ano de 2015 (Figura 2). Diante disso, a área Grecco mantevese entre o mais afetado durante 3 anos consecutivos. As áreas Madruga, Centro, Carvalheira e Residência, durante 2 anos consecutivos, 2015 e 2016, sendo que a área Residência atingiu 188 casos notificados em 2015.

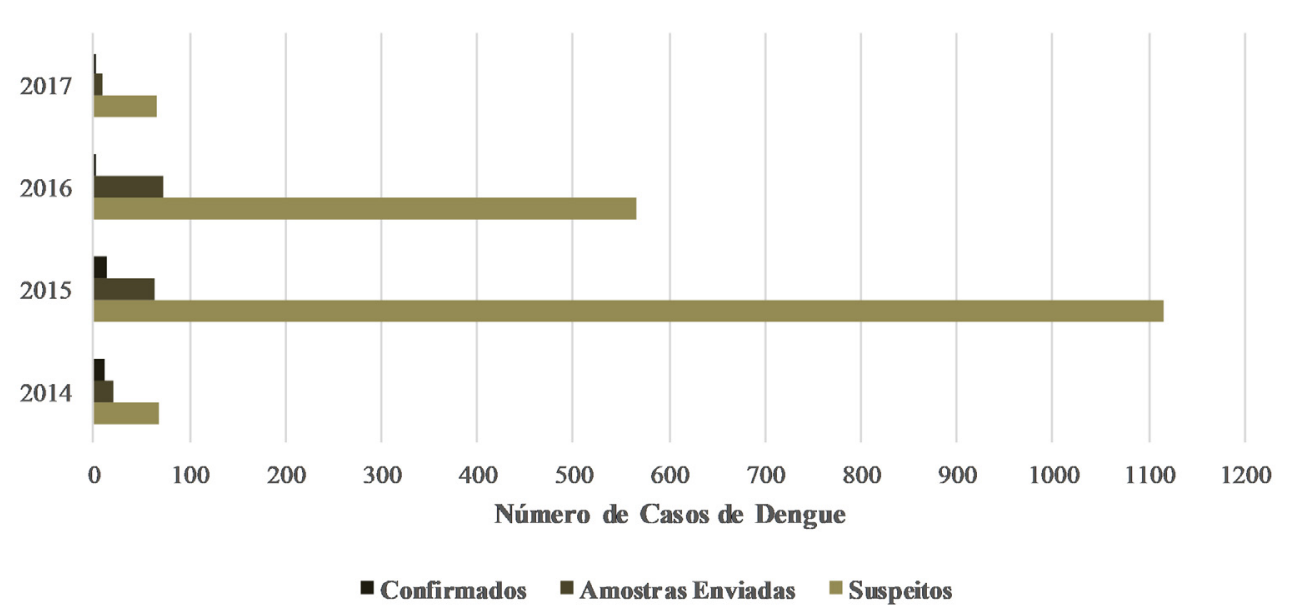

Figura 1. Número de notificações de casos de dengue confirmados das amostras de sangue enviadas para análise e casos suspeitos de dengue, nos anos de 2014-2017.

Total de casos suspeitos de dengue, por área (2014-2015)

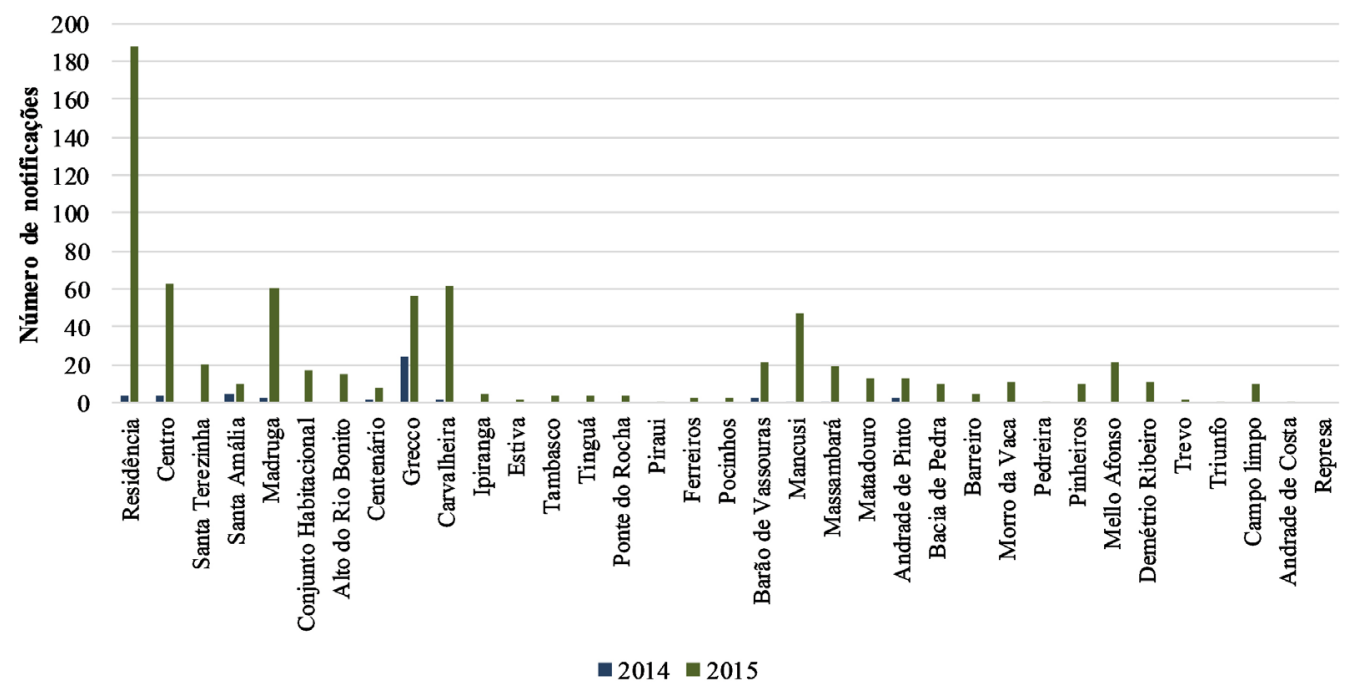

Figura 2. Número de notificações de casos de suspeita de dengue, nos períodos de 2014-2015, por área, no município de Vassouras, RJ. 
Total de casos suspeitos de dengue, por área (2016-2017)

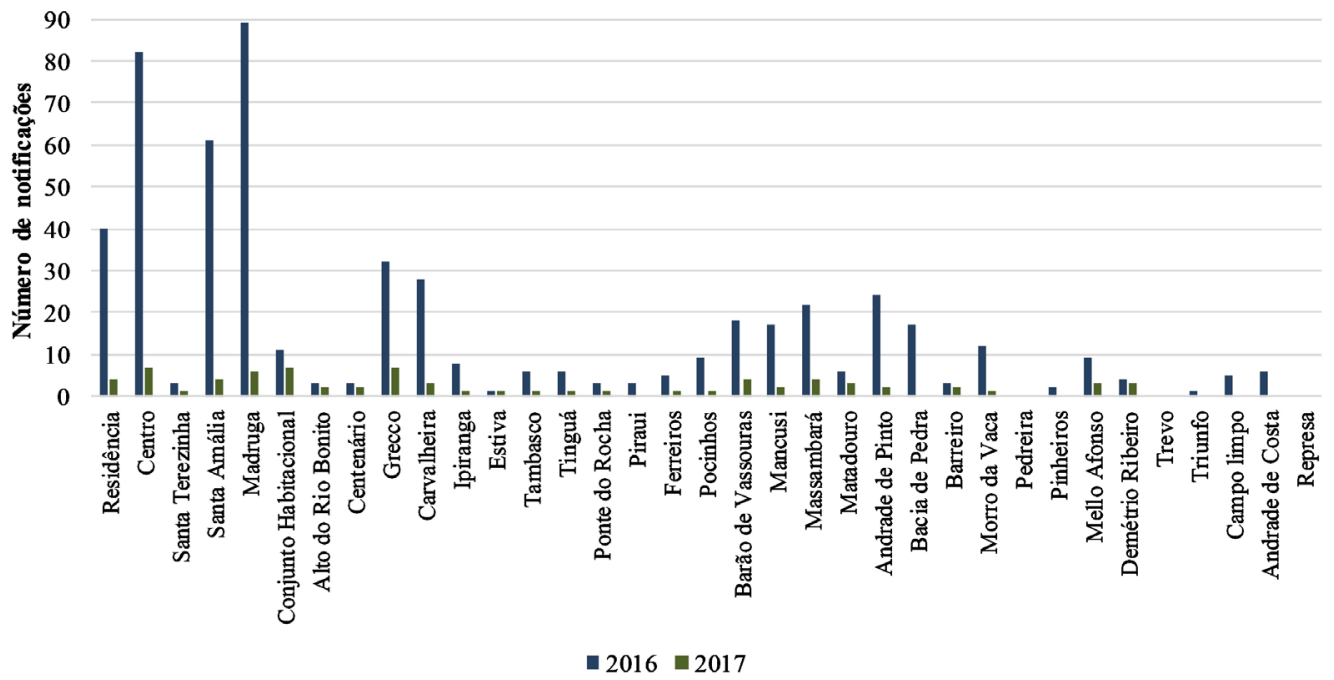

Figura 3. Número de notificações de casos de suspeita de dengue, nos períodos de 2016-2017, por área, no município de Vassouras, RJ.

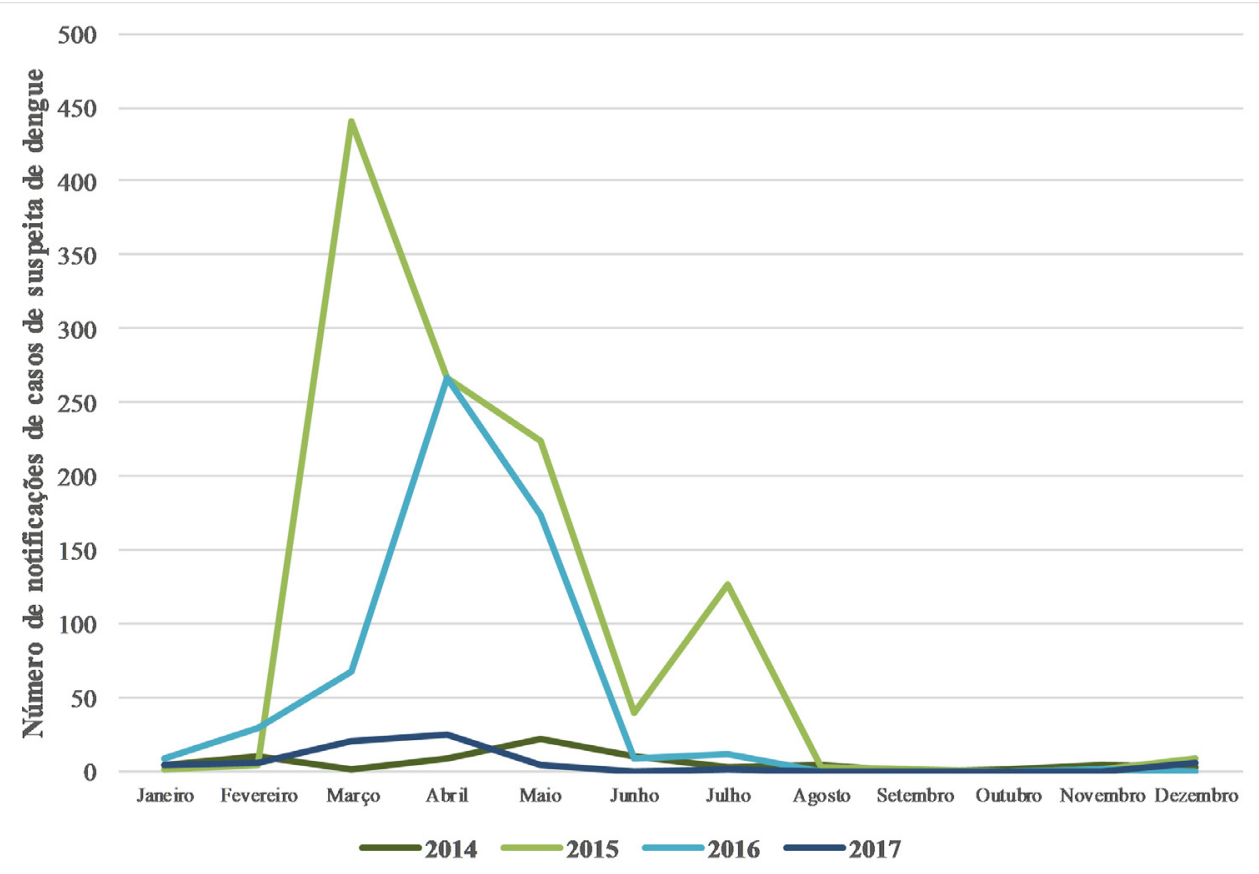

Figura 4. Número de notificações de casos de suspeita de dengue, por mês, nos anos de 2014-2017.

Estes dados colocam as áreas citadas acima como as de maior preocupação e de necessidade de políticas de saúde pública e prevenção.

No estudo dos meses e períodos do ano com maior registro de notificações de casos de suspeita de dengue, tem-se 2014 como o maior número de registros, nos meses de abril, maio e junho. Em 2015 e 2016, foram os meses de março, abril e maio, e com um aumento significativo de notificações de casos de dengue em julho. Já em 2017, os meses destacados foram março e abril. Considerando-se que o período de incubação da dengue no homem, segundo o Ministério da Saúde 6, varia de 4 a 10 dias, com média de 5 a 6 dias, pode-se afirmar que o período de maior contágio pelo vírus da dengue no município de Vassouras ocorreu na estação do outono (Figura 4).

\section{Discussão}

No ano de 2013 o município de Vassouras apresentou 1175 casos de suspeita de dengue, segundo 
dados obtidos pelos boletins epidemiológicos do centro de vigilância em saúde municipal. Em comparação ao número de casos registrados em 2014, notou-se uma grande redução, sendo notificados 68 casos no município, dados que corroboram com os resultados da Superintendência de Vigilância em Saúde (SVS), que mostrou uma redução significativa no número de casos de dengue no estado do Rio de Janeiro no ano de 2014 em comparação com o ano de $2013^{16}$. Esse decréscimo pode ter ocorrido em consequência das intensas campanhas de conscientização e alertas à população do município iniciadas no ano de 2013.

Com relação ao ano de 2015, observou-se um aumento nos registros, de acordo com os dados obtidos pelos boletins epidemiológicos no centro de vigilância em saúde municipal, quando comparado ao ano anterior. Esse crescimento ocorreu em muitos municípios localizados na região sudeste do Brasil, e pode ter sido provocado pela crise de abastecimento de água que ocorreu no Estado de São Paulo e regiões, levando a população a armazenar água da chuva de maneira inadequada ${ }^{17}$, e possivelmente favorecendo a proliferação do $A$. aegypti ${ }^{18}$.

Além disso, foi possível perceber uma relação entre o período do ano em que se concentraram os casos notificados e as estações chuvosas, altas temperaturas e ventos, ocorrendo predominantemente nos meses de março, abril e maio. Desde 1954-1958 que as epidemias de dengue no sudeste asiático, assim como nas décadas de 1980 e 1990, no México, Brasil e Caribe foram registradas em estações chuvosas ${ }^{19}$. A reemergência e disseminação da dengue continuam sendo desafios para a saúde pública brasileira, assim sendo, considerar as notificações dos casos, sua ocorrência por área e estações do ano, poderão ser uma ferramenta auxiliar na vigilância da dengue e o sistema de saúde dos municípios no acompanhamento efetivo desta arbovirose.

\section{Conclusão}

Este estudo levantou os casos de dengue notificados no município de Vassouras nos anos de 20142017. Os dados indicaram que das 35 áreas levantadas neste estudo, o Centro, Santa Amália, Madruga, Grecco, Carvalheira e Residência merecem uma atenção especial, tendo em vista a recorrência destes entre as áreas mais atingidas com casos de dengue. O outono foi a estação mais crítica. Estes resultados poderão auxiliar e possibilitar o aprimoramento das medidas de controle do vetor e prevenção da doença, pois ressaltam a importância epidemiológica desta doença no município e pode direcionar as políticas públicas de combate ao vetor às regiões mais afetadas, tornando mais efetivas as ações da secretaria municipal de saúde, da população e da comunidade científica.

\section{Agradecimentos}

Os autores agradecem o suporte financeiro da Fundação de Amparo à Pesquisa do Estado do Rio de Janeiro (FAPERJ) ao projeto "Novas estratégias para o controle do mosquito Aedes aegypti, vetor da Dengue, Chikungunya e do vírus Zika: uma abordagem integrada/Rede ZIKA\#1" e bolsa PIBIC/FAPERJ; e à Fundação Educacional Severino Sombra (FUSVE) pela bolsa PIBIC/FUSVE.

\section{Referências}

1. Figueiredo LTM, Batista WC, Igarashi A. Detection and identification of dengue virus isolates from Brazil by a simplified reverse transcription - polymerase chain reaction (RT-PCR) method. Rev Inst Med Trop 1997; 39(2):79-84.

2. Instituto Nacional de Meteorologia [Internet]. Balanço hídrico climático da estação de Vassouras, RJ [Acesso em 15 Fev 2015]. Disponível em: http:// www.inmet.gov.br

3. Viana DV, Ignotti E. A ocorrência da dengue e variações meteorológicas no Brasil: revisão sistemática. Rev Bras Epidemiol 2013;16(2):240-56.

4. Silva-Voorham JM da, Tami A, Juliana AE, Rodenhuis-Zybert IA, Wilschut JC, Smit JM. Dengue: a growing risk to travellers to tropical and sub-tropical regions. Ned Tijdschr Geneeskd 2009;153: A778.

5. Ribeiro AF, Marques GRAM, Voltolini JC, Condino MLF. Associação entre incidência de dengue e variáveis climáticas. Rev Saúde Pública 2006; 40(4):671-6.

6. Brasil, Ministério da Saúde, Secretária de Vigilância em Saúde. Dengue: situação epidemiológica e a importância da assistência aos pacientes [Internet]. Mar. 2008. Disponível em: www.combateadengue.com.br/ arquivos/ sobre-dengue.pps. Acesso em 20 Mar. 2019.

7. Osanai CH, Travassos da Rosa AP, Tang AT, Amaral RS do, Passos AD, Tauil PL. Surto de dengue em Boa Vista, Roraima: nota previa. Rev Inst Med Trop 1983;25(1):53-4.

8. Serufo JC, Nobre V, Rayes A, Marcial TM, Lambertucci, JR. Dengue: uma nova abordagem. Rev Soc Bras Med Trop.2000; 33(5):465-76.

9. Brasil, Ministério da Saúde, Secretária de Vigilância em Saúde, Departamento de vigilância Epidemiológica. Doenças infecciosas e parasitarias: guia de bolso. $7^{\mathrm{a}}$ ed. rev. Brasília: Ministério da Saúde; 2008. $372 \mathrm{p}$.

10. Marzochi KBF. Dengue: classificação clínica. Cad Saúde Pública 1991;7(3):409-15.

11. Lupi O, Carneiro CG, Coelho ICB. Manifestações mucocutâneas da dengue. Ann Bras Dermatol 2007;82(4):291-305.

12. World Health Organization. 1997. Dengue hemorrhagic fever: diagnosis, treatment, prevention and control. Disponível em: https://apps.who.int/iris/ handle/10665/41988.

13. Mendonca FA, Souza AVE, Dutra DA. Saúde pública, urbanização e dengue no Brasil. Soc Nat 2009; 21(3):257-69.

14. Barreto ML, Teixeira MG. Dengue no Brasil: situação epidemiológica e contribuições para uma agenda de pesquisa. Estud Av 2008;22(64):53-72.

15. Instituto Brasileiro de Geografia e Estatística - IBGE. Indicadores sociais municipais: uma análise dos resultados do universo do censo demográfico 2010. Rio de Janeiro: IBGE; 2011. Disponível em: http://biblioteca.ibge.gov. br/visualizacao/livros/liv54598.pdf

16. Brasil, Ministério da Saúde, Secretaria de Vigilância em Saúde. Monitoramento dos casos de dengue até a semana epidemiológica (SE) 38 e febre chikungunya até a SE 39 de 2014. Bol Epidem 2014;45:23.

17. Cambricoli, F. Com impacto da crise hídrica, casos de dengue triplicam 
em SP. O Estado de São Paulo, São Paulo, 12 de março de 2015.

18. World Health Organization. Chikungunya [Internet]. Genebra: WHO.

2017. Disponível em: https://www.who.int/news-room/fact-sheets/detail/

chikungunya

19. Donalísio MR, Glasser CM. Vigilância entomológica e controle de vetores do dengue. Rev Bras Epidemiol 2002;5(3):259-79. 